\title{
PENERAPAN MODEL PEMBELAJARAN INKUIRI TERBIMBING DENGAN MEDIA LABORATORIUM VIRTUAL (PhET) UNTUK MENINGKATKAN HASIL BELAJAR, KETERAMPILAN PROSES SAINS DAN MINAT BELAJAR SISWA PADA POKOK BAHASAN ELASTISITAS
}

Mitha Azizaturredha ${ }^{1 *}$, Sri Fatmawati ${ }^{2}$, dan Hadma Yuliani ${ }^{3}$

${ }^{1,2,3}$ Prodi Pendidikan Fisika IAIN Palangka Raya, Indonesia

Email: mitha.redha07@gmail.com

\section{Info Artikel}

Diterima:

22 Desember 2018

Disetujui:

7 Januari 2019

Dipublikasikan:

\begin{abstract}
Abstrak:
Penelitian ini bertujuan untuk melihat penerapan model pembelajaran inkuiri terbimbing dengan media laboratorium virtual (PhET) untuk meningkatkan hasil belajar, keterampilan proses sains dan minat belajar siswa pada pokok bahasan elastisitas. Penelitian ini dilakukan dengan pendekatan pra-eksperimental design yaitu one group pretest-posttest design. Populasi penelitian adalah siswa kelas XI MIPA MAN Kota Palangka Raya tahun Ajaran 2018/2019. Teknik pengambilan sampel dengan menggunakan purposive sampling yang terdiri atas satu kelas yaitu XI MIPA 2. Teknik analisis data yang digunakan adalah uji n-gain. Hasil penelitian yang diperoleh penerapan model pembelajaran inkuiri terbimbing dengan media laboratorium virtual (PhET) dapat meningkatkan hasil belajar, keterampilan proses sains dan minat belajar siswa pada pokok bahasan elastisitas.
\end{abstract}

Kata kunci: inkuiri terbimbing, phet, keterampilan proses sains, minat belajar

\begin{abstract}
:
This study aims to look at the application of guided inquiry learning models with virtual laboratory media (PhET) to improve learning outcomes, science process skills and student learning interests on the subject matter of elasticity. This research was conducted with a preexperimental design approach, one group pretest-posttest design. The study population was students of class XI MIPA MAN KOTA Palangka Raya Academic Year 2018/2019. The sampling technique used purposive sampling consisting of one class, namely XI MIPA 2. The data analysis technique used is n-gain test. The results of the study obtained by applying the guided inquiry learning model with virtual laboratory media (PhET) can improve learning outcomes, science process skills and student learning interests on the subject matter of elasticity.
\end{abstract}

Keywords: guided inquiry, phet, science process skills, interest in learning 


\section{Pendahuluan}

Proses pembelajaran fisika menekankan pada pemberian pengalaman secara langsung untuk mengembangkan kompetensi agar siswa dapat memahami kejadian yang berhubungan dengan aktivitas di kehidupan nyata secara ilmiah (Depdiknas, 2006). Salah satu upaya yang dapat dilaksanakan dalam pembelajaran fisika adalah dengan menggunakan model inkuiri, dalam hal ini adalah inkuiri terbimbing.

Inkuiri terbimbing adalah proses pembelajaran yang merupakan seluruh aktivitasnya dilakukan oleh siswa seperti perencanaan investigasi, observasi, menganalisis, menafsirkan data, mengajukan jawaban, merumuskan kesimpulan, dan berkomunikasi. Guru memainkan peran sebagai motivator yang mengarahkan dan membimbing siswa baik melalui prosedur lengkap atau pertanyaan langsung selama proses penyelidikan (Sularso, et al., 2017).

Suatu model pembelajaran dapat didukung oleh suatu media pembelajaran. Menurut penelitian Kusdiastuti dkk (2016) model pembelajaran inkuiri yang dibantu oleh media pembelajaran berpengaruh terhadap penguasaan konsep Fisika siswa. Berbagai fasilitas media pembelajaran saat ini telah tersedia untuk membantu proses pembelajaran, misalnya dengan menggunakan powerpoint, adobe flash, dan lain-lain. Salah satu media pembelajaran yang dapat digunakan yaitu laboratorium virtual.

Laboratorium virtual memberi siswa pengalaman maya yang berarti dan menyajikan konsep, prinsip, dan proses penting. Dengan menggunakan laboratorium virtual, siswa memiliki kesempatan untuk mengulang eksperimen yang salah atau untuk memperdalam pengalaman yang dimaksud (Bajpai \& Kumar, 2015).

Salah satu media simulasi yang mudah diunduh adalah PhET. Simulasi interaktif PhET adalah rangkaian besar simulasi kualitas profesional untuk pengajaran dan pembelajaran yang didistribusikan dari situs web PhET http://PhET.colorado.edu. Belajar dengan menggunakan simulasi PhET membuat siswa tertarik dan semangat untuk melakukan kegiatan laboratorium sehingga dapat membantu dalam menyelesaikan kegiatan belajar siswa (Supurwoko, et al., 2017).
Keterampilan proses adalah keterampilan siswa untuk mengelola hasil (perolehan) yang didapatkan dalam kegiatan belajar mengajar agar dapat memberi kesempatan yang seluas-luasnya kepada siswa untuk mengamati, menggolongkan, menafsirkan, meramalkan, menerapkan, merencanakan penelitian/eksperimen dan mengkomunikasikan hasil percobaannya tersebut (Azhar, 1993).

Minat sangat mempengaruhi proses dan hasil belajar siswa. Jika seorang siswa tidak berminat untuk mempelajari suatu hal, ia tidak dapat diharapkan akan berhasil dengan baik didalam mempelajari hal tersebut. Sebaliknya, jika seorang siswa mempelajari suatu hal dengan minat, maka hasil yang diharapkan akan lebih baik (Ahmadi \& Prasetya, 1997).

Model pembelajaran inkuiri terbimbing dan media laboratorium virtual PhET diharapkan mampu meningkatkan kualitas siswa pada materi elastisitas. Maka, tujuan penelitian ini adalah untuk mengetahui (1) Ada atau tidaknya peningkatan setelah menerapkan model pembelajaran inkuiri terbimbing dengan media laboratorium virtual $(\mathrm{PhET})$ terhadap hasil belajar siswa pada pokok bahasan elastisitas, (2) Ada atau tidaknya peningkatan setelah menerapkan model pembelajaran inkuiri terbimbing dengan media laboratorium virtual (PhET) terhadap keterampilan proses sains siswa pada pokok bahasan elastisitas dan (3) Ada atau tidaknya peningkatan setelah menerapkan model pembelajaran inkuiri terbimbing dengan media laboratorium virtual (PhET) terhadap minat belajar siswa pada pokok bahasan elastisitas.

\section{Metode Penelitian}

Jenis penelitian yang akan dilaksanakan yaitu penelitian eksperimen dengan pendekatan pra-eksperimental design. Penelitian dengan pendekatan pra-eksperimental design yang dipilih adalah satu kelompok prates-postes (One-Group Pretest-Posttest Design). Desain ini dapat dituliskan sebagai berikut (Arikunto, 2006).

Tabel 1. Desain Penelitian Satu Kelompok Prates-Postes

\begin{tabular}{ccc}
\hline Pretest & Perlakuan & Postest \\
\hline $\mathbf{O}_{1}$ & $\mathrm{X}$ & $\mathbf{O}_{2}$ \\
\hline
\end{tabular}


$\mathrm{O}_{1}$ adalah pretest yang dikenakan pada kelas $\mathrm{A}, \mathrm{O}_{2}$ adalah posttest yang dikenakan pada kedua kelompok $\mathrm{A}, \mathrm{X}$ adalah perlakuan menggunakan model pembelajaran inkuiri terbimbing dengan media pembelajaran laboratorium virtual $(P h E T)$.

Penelitian ini dilaksanakan di MAN Kota Palangka Raya pada Tahun Ajaran 2018/2019 semester I. Populasi dalam penelitian ini adalah seluruh siswa kelas XI MIPA MAN Kota Palangka Raya Tahun Ajaran 2018/2019 yang terdiri dari 5 kelas. Peneliti dalam mengambil sampel menggunakan teknik purposive sampling. Kelas sampel yang terpilih adalah kelas XI MIPA 2.

Teknik pengumpulan data dilakukan dengan menggunakan instrumen penelitian, yaitu tes hasil belajar fisika siswa, tes dan lembar pengamatan keterampilan proses sains dan angket minat belajar siswa. Tes yang digunakan berupa soal uraian yang telah diuji keabsahan datanya. Uji keabsahan data meliputi validitas, realibilitas, daya pembeda dan tingkat kesukaran.

Uji gain dilakukan untuk mengetahui peningkatan hasil belajar, keterampilan proses sains dan minat belajar siswa sebelum dan sesudah pembelajaran dihitung dengan rumus gain ternormalisasi. Persamaan untuk perhitungan gain disajikan dalam rumus berikut (Sundayana, 2014).

$$
g=\frac{S_{\text {post }}-S_{\text {pre }}}{S_{\text {maks }}-S_{\text {pre }}}
$$

Tingkat perolehan skor dikategorikan atas tiga kategori, yaitu:

- $\quad$ Tinggi : $g>0,7$

- $\quad$ Sedang : 0,3 $<\mathrm{g}<0,7$

- Rendah : $\mathrm{g}<0,3$

\section{Hasil Penelitian dan Pembahasan}

Data yang dideskripsikan pada penelitian ini meliputi data hasil belajar, data keterampilan proses sains dan data minat belajar siswa.

\section{Hasil Belajar}

Berdasarkan data hasil penelitian berupa hasil belajar fisika yang diperoleh dari data nilai rata-rata pretest, posttest, gain dan $\mathrm{N}$ gain.
Tabel 2. Nilai rata-rata pretest, posttestt, gain dan $\mathrm{N}$-gain tes hasil belajar

\begin{tabular}{ccccc}
\hline \multirow{2}{*}{ Data } & \multicolumn{4}{c}{ Rata-Rata } \\
\cline { 2 - 5 } & Pretest & Posttest & Gain & N-Gain \\
\hline Hasil & 25,82 & 60,39 & 34,57 & 0,47 \\
Belajar & & &
\end{tabular}

Tabel 2. menunjukkan nilai rata-rata ngain hasil belajar siswa sebesar 0,47 dengan kategori sedang. Hal ini menunjukkan bahwa terdapat peningkatan hasil belajar kognitif siswa sebelum dan sesudah diberikan perlakuan dengan menggunakan model pembelajaran inkuiri terbimbing dengan media laboratorium virtual (PhET) dikarenakan, siswa belajar secara berkelompok yang menuntut siswa untuk dapat bekerja sama dan bertanggung jawab dalam kelompok masing-masing. Siswa dapat membangun pengetahuannya sendiri dengan pengalaman langsung dan konsep-konsep yang telah diperoleh diperkuat dengan penggunaan media laboratorium virtual $(P h E T)$. Proses pembelajaran inkuiri langsung melibatkan siswa dalam pembelajaran aktif untuk membangun pengertian dan pengetahuan yang baru (Toharudin, 2011).

Hasil penelitian ini sejalan dengan hasil penelitian yang dilakukan oleh Pranowo (2017) inkuiri terbimbing berbantuan multimedia dapat meningkatkan pemahaman konsep siswa. Hal ini juga sejalan dengan penelitian yang dilakukan Tuysuz (2010) bahwa pelaksanaan pembelajaran dengan laboratorium virtual berpengaruh positif terhadap prestasi siswa. Penelitian yang dilakukan Yuliani (2017) juga mengungkapkan bahwa pembelajaran Fisika menggunakan media animasi Macromedia Flash - MX dan gambar dapat meningkatkan pemahaman konsep Fisika.

\section{Keterampilan Proses Sains}

Berdasarkan data hasil penelitian berupa keterampilan proses sains yang diperoleh dari data nilai rata-rata pretest, posttest, gain dan N-gain.

Tabel 3. Nilai rata-rata pretest, posttestt, gain dan $\mathrm{N}$-gain keterampilan proses sains

\begin{tabular}{ccccc}
\hline \multirow{2}{*}{ Data } & \multicolumn{4}{c}{ Rata-Rata } \\
\cline { 2 - 5 } & Pretest & Posttest & Gain & N-Gain \\
\hline KPS & 37,14 & 64,04 & 26,89 & 0,42 \\
\hline
\end{tabular}


Tabel 3. menunjukkan nilai rata-rata $\mathrm{n}$ gain keterampilan proses sains siswa sebesar 0,42 dengan kategori sedang. Hal ini menunjukkan bahwa terdapat peningkatan keterampilan proses sains siswa sebelum dan sesudah diberikan perlakuan dengan menggunakan model pembelajaran inkuiri terbimbing dengan media laboratorium virtual $(P h E T)$ dikarenakan, langkah-langkah pada model pembelajaran inkuiri terbimbing dapat memfasilitasi siswa dalam mengembangkan keterampilan proses sains. Siswa tidak hanya memperoleh sejumlah pengetahuan saja, tetapi juga pentingnya proses perolehan pengetahuan tersebut. Sa'ud (2011) mengatakan pengetahuan bukanlah sejumlah fakta yang didapat dari hasil mengingat, akan tetapi hasil dari proses menemukan sendiri.

Hasil penelitian ini sejalan dengan hasil penelitian yang dilakukan oleh Saputra dkk (2016) yang menyebutkan bahwa perangkat pembelajaran yang dilengkapi $\mathrm{PhET}$ berbasis inkuiri dapat meningkatkan keterampilan proses sains siswa. Hal ini juga sejalan dengan penelitian yang dilakukan Koksal dan Berberoglu (2014) bahwa inkuiri terbimbing dapat membantu dalam mengembangkan keterampilan proses sains siswa. Selain itu penelitian yang dilakukan Yuliani dkk (2017) mengemukakan bahwa model inkuiri dengan pendekatan saintifik juga dapat meningkatkan keterampilan berfikir kreatif pada siswa sekolah menengah di Palangka Raya.

\section{Minat Belajar}

Berdasarkan data hasil penelitian berupa minat belajar fisika yang diperoleh dari data nilai rata-rata pretest, posttest, gain dan $\mathrm{N}$ gain.

Tabel 4. Nilai rata-rata pretest, posttestt, gain dan $N$-gain minat belajar

\begin{tabular}{ccccc}
\hline \multirow{2}{*}{ Data } & \multicolumn{4}{c}{ Rata-Rata } \\
\cline { 2 - 5 } & Pretest & Posttest & Gain & N-Gain \\
\hline $\begin{array}{c}\text { Minat } \\
\text { Belajar }\end{array}$ & 55,35 & 59,93 & 4,57 & 0,11 \\
\hline
\end{tabular}

Tabel 4. menunjukkan nilai rata-rata $n-$ gain minat belajar siswa sebesar 0,11 dengan kategori rendah. Hal ini menunjukkan bahwa terdapat peningkatan minat belajar siswa sebelum dan sesudah diberikan perlakuan dengan menggunakan model pembelajaran inkuiri terbimbing dengan media laboratorium virtual $(P h E T)$ dikarenakan, penggunaan media laboratorium virtual (PhET) yang tergolong baru untuk siswa. Pembelajaran yang santai dan menyenangkan juga menjadi salah satu faktor meningkatnya minat belajar siswa. Tuysuz (2010) mengatakan penggunaan laboratorium virtual dapat mengatasi eksperimen yang berbahaya, sulit atau tidak mungkin, dan juga memiliki kelebihan dari sudut pandang waktu, keamanan, biaya dan motivasi.

Hasil penelitian ini sejalan dengan hasil penelitian yang dilakukan oleh As'ad (2015) yang menyebutkan bahwa pembelajaran inkuiri terbimbing memberikan pengaruh yang positif terhadap minat belajar siswa. Sari dkk (2017) mengatakan bahwa dengan penggunaan media pembelajaran juga dapat meningkatkan motivasi belajar siswa khususnya pada mata pelajaran fisika.

\section{Simpulan}

Berdasarkan hasil penelitian dan analisis data yang telah dilakukan, dapat diambil kesimpulan. (1) Terdapat peningkatan hasil belajar kategori sedang dengan nilai ngain 0,47. (2) Terdapat peningkatan keterampilan proses sains kategori sedang dengan nilai n-gain 0,42 . (3) Terdapat peningkatan minat belajar kategori rendah dengan nilai $\mathrm{n}$-gain 0,11 . Penggunaan media untuk melengkapi suatu model pembelajaran dinilai penting maka peneliti menyarankan penggunaan media yang inovatif dapat diterapkan dalam pembelajarn agar siswa dapat memahami pembelajaran dengan lebih mudah.

\section{Daftar Pustaka}

Ahmadi, A. \& Prasetya, J.T. (1997). Strategi belajar mengajar. Bandung: Pustaka Setia.

Arikunto, S. 2006. Prosedur penelitian. Jakarta : Rineka Cipta.

Azhar, L.M. (1993). Proses belajar mengajar pola CBSA. Surabaya: Usaha Nasional.

Bajpai, M., dan Kumar, A. (2015). Effect of virtual laboratory on students' conceptual achievement in physics International Journal of Current Research, 7 (2), 12808-12813. 
Koksal, E. A. \& Berberoglu, G. (2014). The effect of guided inquiry instruction on $6^{\text {th }}$ grade turkish students' achievement, science process skills, and attitude toward science International Journal of Science Education, 36 (1), 66-78.

Kusdiastuti, M., Harjono, A., Sahidu, H., dan Gunawan. (2016). Pengaruh model pembelajaran inkuiri berbantuan laboratorium virtual terhadap penguasaan konsep fisika peserta didik Jurnal Pendidikan Fisika dan Teknologi, 2 (3): 116-122.

Pranowo, T.E., Siahaan, P. \& Setiawan, W. (2017). Penerapan multimedia dalam pembelajaran IPA dengan metode inkuiri terbimbing untuk meningkatkan pemahaman konsep perpindahan kalor siswa kelas VII Jurnal Wahana Pendidikan Fisika, 2 (1), 1-4.

Rusman. (2013). Belajar dan pembelajaran berbasis komputer. Bandung: Alfabeta.

Salahudin As'ad (2015). Pengaruh pembelajaran inkuiri terbimbing terhadap minat dan hasil belajar peserta didik kelas X teknik audio video SMK N 3 Mataram mata pelajaran teknik elektronika dasar. Skripsi, tidak dipublikasikan. Universitas Negeri Yogyakarta.

Supurwoko, Cari, Sarwanto, Sukarmin, Budiharti, R. \& Dewi, T.S. (2017). Virtual lab experiment: physics educational technology (PhET) photo electric effect for senior high school International Journal of Science and Applied Science: Conference Science, 2 (1): 381-386.

Saputra, T.B., Nur, M. \& Purnomo, T. (2016). Desain riset perangkat pembelajaran menggunakan media kit listrik yang dilengkapi PhET berbasis inkuiri untuk melatihkan keterampilan proses sains Unnes Science Education Journal, 5 (3), 1331-1342.

Sari, N., Suryanti, K., Manurung, S.M. \& Sintia (2017). Analisis penggunaan media pembelajaran untuk meningkatkan motivasi peserta didik terhadap pembelajaran fisika kelas XI MIPA 1 SMA Titian Teras Muaro Jambi Jurnal Pendidikan Fisika dan Keilmuan, 3 (2), 110-112.

Sa'ud, U.S. (2011). Inovasi pendidikan. Bandung: Alfabeta.

Semiawan, C., Tangyong, A.F., Belen, S., Matahelemual, Y., dan Suseloardjo, W. (1992). Pendekatan keterampilan proses. Jakarta: Gramedia.

Sularso, Sunarno, W. \& Sarwanto. (2017). Understanding students' concepts through guided inquiry learning and free modified inquiry on static fluid material International Journal of Science and Applied Science: Conference Science, 2 (1): 363-367.

Sundayana, R. (2014). Satatistika penelitian pendidikan. Bandung: Alfabeta.

Toharudin, U. \& Hendrawati, S. (2011). Membangun literasi sains peserta didik. Bandung: Humaniora.

Trianto. (2010). Model pembelajaran terpadu. Jakarta: Bumi Aksara.

Tuysuz, C. (2010). The effect of the virtual laboratory on students' achievement and attitude in chemistry International Online Journal of Education Science, 2 (1), 37-53.

Yuliani, H. (2017). Pembelajaran fisika menggunakan media animasi macromedia flash - mx dan gambar untuk meningkatkan pemahaman konsep mahasiswa. Jurnal Ilmiah Pendidikan Fisika Al-BiRuNi, 06 (1), 13-21.

Yuliani, H., Mariati, Yulianti, R. \& Herianto, C. (2017). Keterampilan berpikir kreatif pada siswa sekolah menengah di Palangka Raya menggunakan pendekatan saintifik Jurnal Pendidikan Fisika dan Keilmuan, 3 (1), 48-56. 